OPEN ACCESS

Edited by:

Benjamin Frey,

University Hospital Erlangen, Germany

Reviewed by:

Jian-Guo Zhou,

University of Erlangen Nuremberg,

Germany

Erik Richard Ladomersky, Northwestern University,

United States

Rimas Vincas Lukas, Northwestern University,

United States

*Correspondence:

Mahua Dey

dey@neurosurgery.wisc.edu

Specialty section:

This article was submitted to

Cancer Immunity and Immunotherapy,

a section of the journal

Frontiers in Oncology

Received: 01 February 2021

Accepted: 19 April 2021

Published: 11 May 2021

Citation:

Lara-Velazquez M, Shireman JM,

Lehrer EJ, Bowman KM,

Ruiz-Garcia H, Paukner MJ,

Chappell RJ and Dey M (2021) A

Comparison Between Chemo-

Radiotherapy Combined With

Immunotherapy and Chemo-

Radiotherapy Alone for the Treatment of Newly Diagnosed Glioblastoma: A Systematic Review and Meta-Analysis.

Front. Oncol. 11:662302.

doi: 10.3389/fonc.2021.662302

\section{A Comparison Between Chemo- Radiotherapy Combined With Immunotherapy and Chemo- Radiotherapy Alone for the Treatment of Newly Diagnosed Glioblastoma: A Systematic Review and Meta-Analysis}

\author{
Montserrat Lara-Velazquez ${ }^{1}$, Jack M. Shireman ${ }^{1}$, Eric J. Lehrer ${ }^{2}$, Kelsey M. Bowman ${ }^{1}$, \\ Henry Ruiz-Garcia ${ }^{3}$, Mitchell J. Paukner ${ }^{4}$, Richard J. Chappell ${ }^{4}$ and Mahua Dey ${ }^{1 *}$ \\ ${ }^{1}$ Department of Neurosurgery, University of Wisconsin School of Medicine \& Public Health, UW Carbone Cancer Center, \\ Madison, WI, United States, 2 Department of Radiation Oncology, Icahn School of Medicine at Mount Sinai, New York, NY, \\ United States, ${ }^{3}$ Department of Neurosurgery and Radiation Oncology, Mayo Clinic, Jacksonville, FL, United States, \\ ${ }^{4}$ Department of Statistics, Biostatistics and Medical Informatics, University of Wisconsin School of Medicine \& Public Health, \\ UW Carbone Cancer Center, Madison, WI, United States
}

Background: Immunotherapy for GBM is an emerging field which is increasingly being investigated in combination with standard of care treatment options with variable reported success rates.

Objective: To perform a systematic review of the available data to evaluate the safety and efficacy of combining immunotherapy with standard of care chemo-radiotherapy following surgical resection for the treatment of newly diagnosed GBM.

Methods: A literature search was performed for published clinical trials evaluating immunotherapy for GBM from January 1, 2000, to October 1, 2020, in PubMed and Cochrane using PICOS/PRISMAMOOSE guidelines. Only clinical trials with two arms (combined therapy vs. control therapy) were included. Outcomes were then pooled using weighted random effects model for meta-analysis and compared using the Wald-type test. Primary outcomes included 1-year overall survival (OS) and progression-free survival (PFS), secondary outcomes included severe adverse events (SAE) grade 3 or higher.

Results: Nine randomized phase II and/or III clinical trials were included in the analysis, totaling 1,239 patients. The meta-analysis revealed no statistically significant differences in group's 1-year OS [80.6\% (95\% Cl: 68.6\%-90.2\%) vs. 72.6\% (95\% Cl: 65.7\%-78.9\%), p = 0.15] or in 1-year PFS [37\% (95\% Cl: $26.4 \%-48.2 \%)$ vs. 30.4\% (95\% Cl: $25.4 \%-35.6 \%) p=$ 0.17 ] when the immunotherapy in combination with the standard of care group (combined therapy) was compared to the standard of care group alone (control). Severe adverse events grade 3 to 5 were more common in the immunotherapy and standard of care group than in 
the standard of care group (47.3\%, 95\% Cl: $20.8-74.6 \%$, vs $43.8 \%, 95 \% \mathrm{Cl}: 8.7-83.1, \mathrm{p}=$ $0.81)$, but this effect also failed to reach statistical significance.

Conclusion: Our results suggests that immunotherapy can be safely combined with standard of care chemo-radiotherapy without significant increase in grade 3 to 5 SAE; however, there is no statistically significant increase in overall survival or progression free survival with the combination therapy.

Keywords: newly diagnosed glioblastoma, immunotherapy, vaccine, chemo-radiotherapy, high-grade glioma, glioma

\section{INTRODUCTION}

Glioblastoma (GBM) is the most common primary and dismal brain cancer in adults, this carries a poor prognosis and median overall survival (OS) (1). It is a highly aggressive and heterogeneous entity that survives even the most eradicative treatments (2-4). Current standard of care for GBM includes safe maximal tumor resection, followed by temozolomide (TMZ) chemotherapy (75 $\mathrm{mg} / \mathrm{m} 2 /$ day for 6 weeks) and concomitant radiation (60 Gy in 30 fractions). TMZ is then followed by six continued maintenance cycles (150-200 mg/m2/day for the first 5 days of a 28-day cycle); accompanied by the antimitotic device tumor treating fields (TTF) (Optune, Novocure Inc) (4-6), which is continued once TMZ is completed. This standard of care with TTF included, achieves a median overall survival of 20.9 months, that is in contrast with the 16 months median survival obtained with surgery and chemoradiotherapy alone (7). However, tumor recurrence happens in the majority of the patients despite the aggressive treatment regimen (8), highlighting a major treatment gap in GBM that has yet to be addressed (9-14). Multiple strategies are being developed with the goal of effectively treating GBM, however, one such strategy that has proven viable in other cancer domains and is currently being heavily investigated is immunotherapy $(6,15)$.

Immunotherapy, is an evolving field of medicine that enhances the activity of select cells in the immune system to recognize, attack, and kill cancer cells via targeted anti-tumorcytotoxicity without harming the normal tissue $(16,17)$. The main promise of immunotherapy is not only to combat tumor growth by eliminating cancer cells, but to keep an army of memory cells to avoid tumor recurrence, a facet of treatment that will be crucial for GBM (18). The discovery of specific tumor associated peptides presented by major histocompatibility complexes (MHC) (19, 20); and inhibition of immune checkpoint molecules (cytotoxic $\mathrm{T}$ lymphocyte antigen 4 (CTLA4) and programmed cell death 1 (PD1) that regulate $\mathrm{T}$ cell activation; opened new doors for the treatment of cancer, by augmenting the natural functions of the immune system $(17,21-$ 23). Biological options of immune-based therapies that have been developed include checkpoint inhibitors, cellular therapies, vaccines, engineered $\mathrm{T}$ cells, small peptide inhibitors of specific pathways, monoclonal antibodies, and cytokine therapy (24-26).

Currently there are no Food and Drug Administration (FDA) approved immunotherapy regimens for the treatment of GBM
(16). Although there are several immune-based therapies currently being tested for GBM, the majority evaluate mainly tolerance and toxicity (16). Even while some immunotherapies have shown promising clinical results when evaluated as a monotherapy, their true impact when combined with, or given alongside of, standard of care is unknown (27). Moreover, only a few of these modalities have progressed to the phase II or III clinical trial setting to systematically test their impact on overall survival, progression of the disease, and severe adverse events when administered in combination with current standard of care (28). Because of this, little is known about the true clinical benefits and toxicity profile of immunotherapy given in combination with chemo-radiotherapy. Ongoing (unpublished) phase II or III clinical trials of immune checkpoint inhibitors used in combination with standard of care for newly diagnosed GBM failed to meet survival expectancy and PFS in MGMT methylated (CheckMate 548, NCT02667587) $(29,30)$ or un-methylated (CheckMate 498, NCT02617589) (31, 32) GBM patients. The randomized trial phase II/III NRGBN007 evaluating ipilimumab and nivolumab versus temozolomide to radiotherapy in un-methylated GBM patients is also ongoing, and the results are awaited with high expectations (33). Unfortunately, most of the results with different immunotherapies in GBM have disappointed the medical community in regards of improving survival for these patients. However, these studies are essential to understand the benefits and the associated risks of immunotherapies in gliomas.

This gap in the knowledge could be masking the full potential of immunotherapy when used as an adjuvant treatment in GBM and can be limiting our ability to make fully informed decisions in regard to adding immunotherapy to the current standard of care for GBM. To address the knowledge gap in this area and to provide a scientific rationale about the possible synergistic effect that chemo-radiation and immunotherapy may have when used together, we performed a systematic review and meta-analysis. We analyzed and compared 1-year overall survival (OS), 1-year progression free survival (PFS) and grade 3 to 5 adverse events, in the immunotherapy plus chemo-radiotherapy regimen (defined as immunotherapy and standard of care or combined group), versus chemo-radiotherapy alone regimen (defined as standard of care or control group), in patients with newly diagnosed GBM. 


\section{MATERIALS AND METHODS}

\section{Study Selection Criteria}

A search strategy was developed using the Population, Intervention, Comparison, Outcome, Study type (PICOS) question format: In newly-diagnosed glioblastoma patients (Population) that receive standard of care with or without immunotherapy (Intervention and Comparison), what are the overall survival, progression free survival and severe adverse events grades 3 to 5 (Study Type) based on results from phase II and III clinical trials (Study type) (Supplementary Table 1).

A literature search in PUBMED and Cochrane was performed by three independent reviewers according to the Preferred Reporting Items for Systematic Reviews and Meta-Analyses (PRISMA) (Figure 1 and Supplementary Table 2) (34) and Meta-Analyses and Systematic Reviews of Observational Studies (MOOSE) (35) (Supplementary Table 3) guidelines. Our search included phase II and/or III clinical trials, published from January 1st 2000 to October 1st 2020. The terms used for literature search included "glioblastoma," OR "newly diagnosed glioblastoma," OR "malignant glioma," AND "radiation" AND "chemotherapy" OR "radio-chemotherapy," AND "immunotherapy". These terms were specifically used as follows in batch searches across both databases: glioblastoma and radio chemotherapy and immunotherapy, newly diagnosed glioblastoma and radio chemotherapy and immunotherapy, newly diagnosed glioblastoma and radio chemotherapy, newly diagnosed glioblastoma and immunotherapy, glioblastoma and immunotherapy, newly diagnosed glioblastoma and radiotherapy, newly diagnosed glioblastoma and chemotherapy and malignant glioma and radio chemotherapy and immunotherapy. Any disagreement was discussed and resolved by the reviewers and senior author. All the articles resulting from our initial search were analyzed for our inclusion and exclusion criteria (Table 1) and only articles that satisfied all our inclusion and exclusion criteria were selected for the final analysis.

\section{Data Extraction}

All data were extracted from the main manuscript and supplementary text, tables, and figures of the included articles. Our primary outcome of interest was clinical efficacy of combined therapy compared with control therapy in patients with newly diagnosed GBM; (as reflected by median and 1-year survival and PFS). Estimation of survival and PFS at 1 year was done by using the software Plot Digitizer ${ }^{\circledR}$ v.2.6.8 in those articles that did not report these parameters as such. OS and PFS were calculated from the data based on date of surgery until event (death or recurrence). The secondary outcome was toxicity, measure as the number and proportion of incidental grades 3 to 5 adverse events by the end of the study in the standard of care and immunotherapy group as compared with the standard of care group alone. Two independent investigators extracted the data (M.L.V and K.M.B), and confirmation of extracted data was done by two other independent reviewers (H.R.G and J.M.S).

\section{Statistical Analysis}

R Studio (36), Version 1.1.383 (Boston, MA) was used to perform the statistical analyses. Generation of random-effects meta-analyses, assessments of heterogeneity and publication bias, and generation of forest plots were conducted as previously described by Lehrer et al. (37) Study arms were compared using the Wald-type test, where the null-hypothesis was rejected for $\mathrm{p}<0.05$.

\section{Quality Evaluation of Clinical Trials}

Publications accepted in the study were methodologically evaluated according to the revised Cochrane risk-of-bias tool for randomized trials (38). This system categorizes the studies in low, unclear or high risk of bias, according to the following parameters: random sequence generation, allocation concealment, blinding of participants and personnel, blinding of outcome assessment (self-reported outcomes and objective measures), incomplete outcome data, selective reporting and other bias. Buchroithner, Cho, Kong, Ursu, and Wakabayashi trials had unclear to high risk of bias in at least three different parameters evaluated, Wheeler and Sampson had high risk of bias in five parameters. Weller and Wen trials had unclear risk of bias in only one parameter, making them the trials with lower risk of bias in the entire study (Supplementary Figure 1).

We also evaluated the quality of the included trials with the Grading of Recommendations, Assessment, Development, and Evaluation (GRADE) system (GRADEpro). For the evaluated outcomes, 1-year OS and PFS were rated with moderate quality, whereas SAEs grades 3 to 5 were rated as low quality (Supplementary Tables 4 and 5).

\section{RESULTS}

\section{Study Characteristics}

Our initial search resulted in 1901 publications (1809 from PUBMED and 92 from Cochrane). Due to duplicity 213 articles were eliminated, while 1631 were eliminated after the title/abstract was screened based on our inclusion and exclusion criteria. A total of 57 papers met our initial screening of the eligibility criteria. The full text of those articles was analyzed and a total of nine articles met all our inclusion and exclusion criteria and were included for final analysis. Of the nine studies included, seven were phase II clinical trials (77.7\%) and two were phase III (22.2\%) (Figure 1 and Table 2). Three studies were conducted in North America (39-41), two in Europe (42-44), three in Asia (45-47), and one in Europe and North America (48). Combining all the studies, a total of 1239 patients were included. There were $583(47 \%)$ patients in the immunotherapy and standard of care group, and $656(52.9 \%)$ in the standard of care group. Of the seven articles that described gender information of the included patients (40, 42-50), 619 (60.5\%) were male and 403 (39.4\%) were female; two articles did not include this information (39, 41). Average age of the patients ranged from 27 years to 72.2 


\section{PRISMA 2009 Flow Diagram}
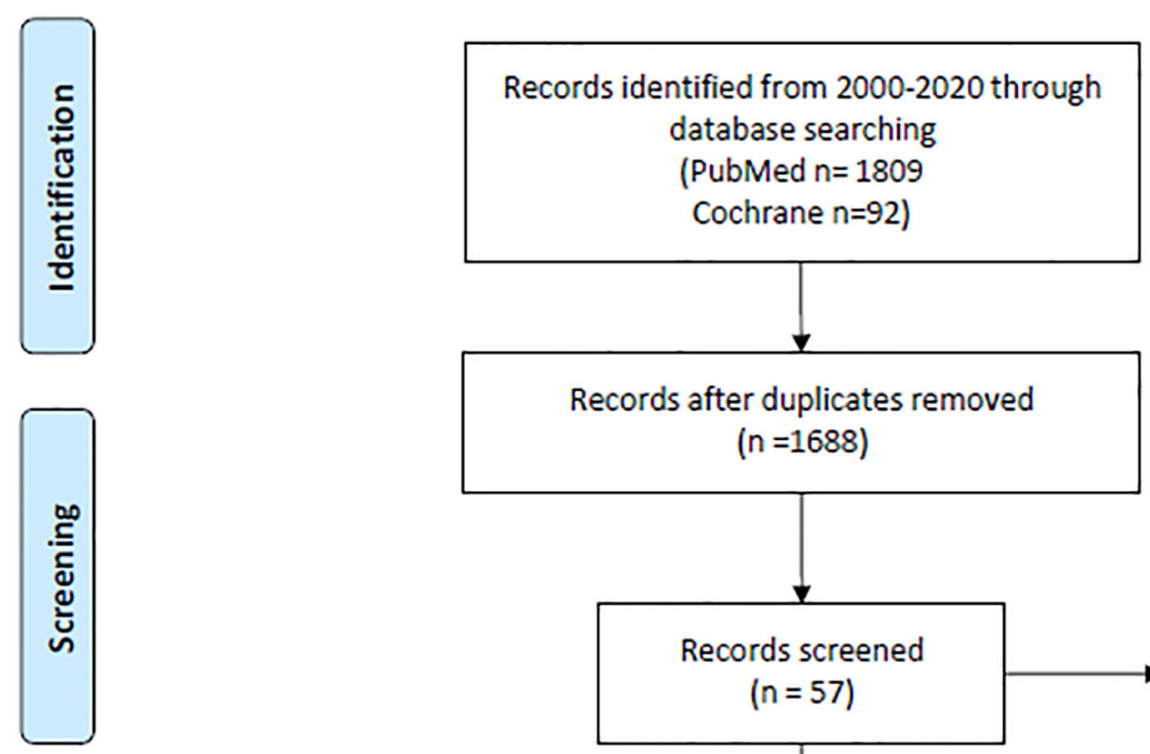
Records after duplicates removed ( $n=1688$ )

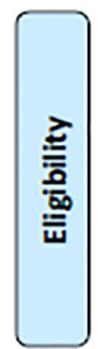

Full-text articles assessed for eligibility

$(n=57)$

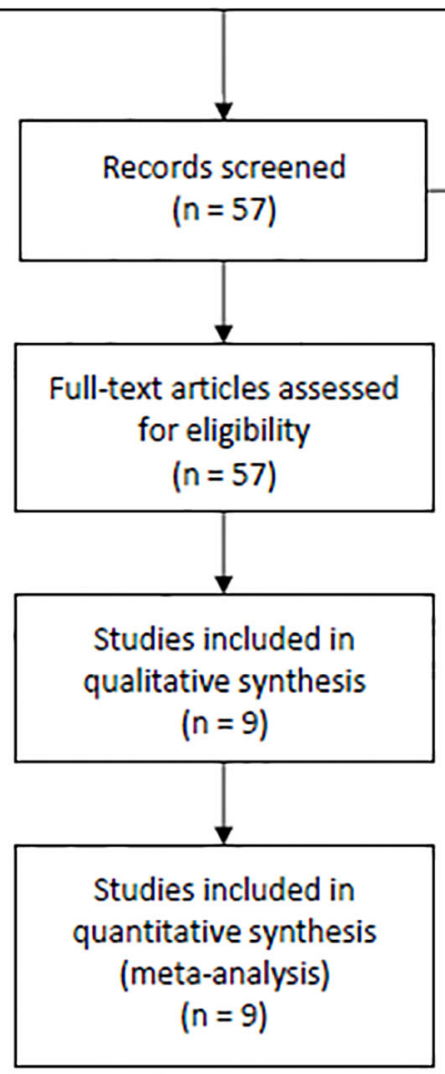

FIGURE 1 | PRISMA diagram describing study design and selection (34).

years. Regarding the immunotherapy approach, four studies used cellular vaccines, two used peptide vaccines, one used immunostimulating oligodeoxynucleotides, one interferon $\beta$, and one gene-mediated cytotoxic immunotherapy. All trials combined one of these regimens in combination with chemoradiotherapy, while a chemoradiotherapy regimen alone group was used as control in all of them. Four immune based approaches were administered intravenously (44.4\%), one cranially (11.1\%), three intradermally (33.3\%), and one intracranially, intravenously and/or orally (11.1\%) (Supplementary Table 6). 
TABLE 1 | Inclusion and exclusion criteria.

\begin{tabular}{ll}
\hline Inclusion & \multicolumn{1}{c}{ Exclusion } \\
\hline $\begin{array}{ll}\text { (1) patients with newly diagnosed GBM } & \text { (1) patients with recurrent GBM } \\
\text { confirmed by pathology } & \\
\text { (2) with no other neurological diseases } & \text { (2) with other neurological diseases } \\
\text { (3) study specifically described as clinical } & \text { (3) study not specified as clinical } \\
\text { phase II or III } & \text { phase II or III } \\
\text { (4) with two arm groups: control and } & \text { (4) with one arm group only } \\
\text { combined } & \text { (5) published in other language } \\
\text { (5) published only in English } & \text { different than English } \\
\text { (6) limited to human subjects } & \text { (6) not limited to human subjects }\end{array}$
\end{tabular}

Finally, we analyzed the clinical trials that used the same immunotherapy strategy. The cellular vaccines subgroup was the only category with enough studies to perform a statistical analysis (four studies total: Buchroithner, Wen, Cho, and Kong) (40, 42, 45, 46).

\section{Clinical Outcomes}

\section{Combined Therapy Was Not Associated With} Significant Improvement in Overall Survival

The 1-year OS was $72.6 \%$ (95\% CI: $65.7 \%-78.9 \%$, I2: $71 \%$ ) versus $80.6 \%$ (95\% CI: $68.6 \%-90.2 \%$, I2: $75 \%$ ) for the control and combined therapy groups, respectively $(p=0.15)$. Publication bias was absent with p-values of 0.89 and 0.72 , respectively. These results are shown in Figure 2. Median OS was 16.9 months in control group vs. 20.1 months in the combined therapy group (Supplementary Table 7).

In the cellular vaccine subgroup analysis, 1-year OS was $71.2 \%$ (95\% CI: $62 \% .1-79.4 \%, \mathrm{I}^{2}=0 \%$ ) versus $76.5 \%$ (95\% CI: $\left.66.8 \%-85 \%, \mathrm{I}^{2}=4 \%\right)$ for the standard of care and immunotherapy groups, respectively $(\mathrm{p}=0.21)$. There was no publication bias with $\mathrm{p}$-values of 0.82 and 0.36 , respectively. These results are shown in Figure 3.

\section{Combined Therapy Was Not Associated With} Significant Improvement in Progression Free Survival The estimated 1-year PFS was 37\% (95\% CI: 26.4-48.2, $\mathrm{I}^{2}=60 \%$ ) versus $30.4 \%$ (95\% CI: $25.4-35.6 ; \mathrm{I}^{2}=0 \%$ ) for the combined therapy and control groups, respectively $(\mathrm{p}=0.17)$. Publication bias was absent with p-values of 0.13 and 0.63 , respectively (Figure 4). Two clinical trials were not included in this analysis since they did not describe PFS information properly for GBM patients $(35,44)$. Median PFS were 8.5 months and 7.7 months in the combined therapy group and control group, respectively (Supplementary Table 7).

In the cellular vaccine subgroup analysis, 1-year PFS was 35\% (95\% CI: $18.2-53.9, \mathrm{I}^{2}=62 \%$ ) versus $26.2 \%$ (95\% CI: $19.8-33.3, \mathrm{I}^{2}=$ $0 \%)$ in the combine therapy group and control group, respectively $(p=0.19)$. No publication bias was present in neither of both groups ( $p=0.73$ and $p=0.27$, respectively) as described in Figure 5.

\section{Combined Therapy Was Not Associated With Significant Increase in Incidence of Grade 3-5 Severe Adverse Events}

Toxicity analysis was performed with data from four clinical trials that described SAE grades 3 to 5 appropriately (40, 42, 46,
48). SAE was $47.3 \%$ (95\% CI: $20.8-74.6, \mathrm{I}^{2}=95 \%$ ) versus $43.8 \%$ (95\% CI: 8.7-83.1, $\mathrm{I}^{2}=94 \%$ ) in the combined therapy group and control group, respectively $(\mathrm{p}=0.81)$. There were not bias associated with publication in these studies $(\mathrm{p}=0.22$ and $\mathrm{p}=$ 0.37 , respectively). These results are depicted in Figure 6. Of the 1110 pooled patients included in this analysis, $184(16.5 \%)$ in the control group versus 201 (18.1\%) patients in combined therapy group had a SAE (Supplementary Table 8).

In the cellular vaccine subgroup analysis, one trial did not include a full description of SAE (45); thus, subgroup analysis was performed with the other three studies $(40,42,46)$. SAEs analysis revealed higher occurrence in the vaccine and standard of care group $\left(57.3 \%, 95 \%\right.$ CI: $\left.51.1-63.4, \mathrm{I}^{2}=0 \%\right)$ when compared to standard of care group (49.6\%, 95\% CI: $0.2-99.8$, $\left.\mathrm{I}^{2}=94 \%\right), \mathrm{p}=0.68$. Publication bias was absent with $\mathrm{p}$-values of 0.19 and 0.78 , respectively. These results are shown in Figure 7.

\section{DISCUSSION}

In this systematic review and meta-analysis, we objectively analyzed the survival, progression free survival, and toxicity profile of immunotherapy in combination with chemoradiation versus chemo-radiotherapy alone in newly diagnosed GBM. In regard to overall survival and progression free survival we found that immunotherapy marginally prolonged both; however, this effect was not statistically significant. We also found that immunotherapy with standard of care does not increase grade 3 to $5 \mathrm{SAE}$ in a statistically significant manner when compared to standard of care alone (Table 3).

As inherent in the nature of a meta-analysis, our overall analysis is limited by the individual limitations of each of the studies included in the analysis. The number of patients treated in each trial varied widely, from 34 patients (45) to 405 patients (48), between trials thus weighing differently on the overall analysis.

The immunotherapy was administered in different ways [intravenous, intradermal, oral $(39,40,42,45-48)$ and intracerebral $(41,44)]$ possibly limiting therapeutic distribution as well as immune cell recruitment and diminished effector function. Furthermore, the targeted dose, as well as the number of doses administered, varied among trials. Although most of the studies administered the immunotherapy agent at minimum two to five times, the total number of doses was patient specific and was dependent on clinical progression or death. There was also a variability in the follow-up period between trials, making the comparison between trials heterogeneous. The timing of when the immunotherapy was initiated varied between trials which could influence the overall toxicity profile of the combined strategy and finally determined the reported SAEs in the trials. Most of the trials used an early start of immunotherapy including: 1 to 2 weeks after chemoradiation (42, 48 ), at the same time as chemoradiation (46), preoperatively (41, 44 ), on alternate days during radiation (47), and between radiotherapy and at the beginning of temozolomide (40). While two studies showed a mid-late start of immunotherapy: within 6 
TABLE 2 | Overall characteristics of the studies.

\begin{tabular}{|c|c|c|c|c|c|c|c|c|c|c|c|}
\hline First Author & Buchroithner & Cho & Kong & Sampson & Ursu & Wakabayashi & Weller & Wen & Wheeler & Total & Median \\
\hline Year & 2018 & 2011 & 2017 & 2010 & 2017 & 2018 & 2017 & 2019 & 2016 & & \\
\hline Trial Phase & $\|$ & $\|$ & III & $\|$ & $\|$ & $\|$ & III & $\|$ & $\|$ & & \\
\hline $\begin{array}{l}\text { Country of } \\
\text { Publication }\end{array}$ & Austria & China & Korea & USA & France & Japan & $\begin{array}{l}\text { Switzerland/ } \\
\text { USA }\end{array}$ & USA & USA & & \\
\hline Age (low limit) & 19 & 14 & 19 & 29 & 42 & 22 & 51 & 22 & 32 & & 27 \\
\hline Age (high limit) & 70 & 70 & 69 & 71 & 78 & 75 & 64 & 81 & 72 & & 72.2 \\
\hline $\begin{array}{l}\text { Patients } \\
\text { Included (n) }\end{array}$ & 76 & 34 & 180 & 35 & 81 & 122 & 405 & 124 & 182 & 1239 & \\
\hline $\begin{array}{l}\text { Immunoteraphy } \\
\text { group (n) }\end{array}$ & 34 & 18 & 91 & 18 & 39 & 59 & 195 & 81 & 48 & 583 & \\
\hline $\begin{array}{l}\text { Immunotherapy } \\
\text { group (\%) }\end{array}$ & 44.73684211 & 52.94117647 & 50.55555556 & 51.42857143 & 48.14814815 & 48.36065574 & 48.14814815 & 65.32258065 & 26.37362637 & & 47 \\
\hline $\begin{array}{l}\text { Control group } \\
\text { (n) }\end{array}$ & 42 & 16 & 89 & 17 & 42 & 63 & 210 & 43 & 134 & 656 & \\
\hline $\begin{array}{l}\text { Control group } \\
\text { (\%) }\end{array}$ & 55.26315789 & 47.05882353 & 49.44444444 & 48.57142857 & 51.85185185 & 51.63934426 & 51.85185185 & 34.67741935 & 73.62637363 & & 52.9 \\
\hline $\begin{array}{l}\text { Immunotherapy } \\
\text { type used }\end{array}$ & $\begin{array}{l}\text { Tumor lysate- } \\
\text { charfed } \\
\text { autologous } \\
\text { dendritic cells } \\
\text { (Audencel) }\end{array}$ & $\begin{array}{l}\text { Whole-cell } \\
\text { lysate } \\
\text { dendritic cell } \\
\text { vaccine }\end{array}$ & $\begin{array}{l}\text { Autologous } \\
\text { cytokine- } \\
\text { induced killer } \\
\text { cells }\end{array}$ & $\begin{array}{l}\text { PEPVIII vaccine (13-amino } \\
\text { acid peptide } w / \text { an } \\
\text { additional terminal cystine } \\
\text { that spans the EGFRvlll } \\
\text { mutation) }\end{array}$ & $\begin{array}{l}\text { Immunostimulating } \\
\text { oligodeoxynucleotides } \\
\text { containing unmethylated } \\
\text { cytoside-guanosine motifs } \\
\text { (CpG-ODN) }\end{array}$ & Interferon $\beta$ & Rindopepimut & $\begin{array}{l}\text { ICT-107 } \\
\text { (autologous } \\
\text { dendritic } \\
\text { cells) }\end{array}$ & $\begin{array}{l}\text { Aglatimagene } \\
\text { besadenovec (AdV- tk) } \\
\text { plus valcyclovir (gene- } \\
\text { mediated cyottoxic } \\
\text { immunotherapy) }\end{array}$ & & \\
\hline Male (n) & 51 & 16 & 102 & NA & 48 & 73 & 254 & 75 & NA & 619 & \\
\hline Male \% & 67.10526 & 47.05882 & 56.66667 & NA & 59.25926 & 59.83607 & 62.71605 & 60.48387 & NA & & 60.5 \\
\hline Female (n) & 25 & 18 & 78 & NA & 33 & 49 & 151 & 49 & NA & 403 & \\
\hline Female $\%$ & 32.89474 & 52.94118 & 43.33333 & NA & 40.74074 & 40.16393 & 37.28395 & 39.51613 & NA & & 39.4 \\
\hline
\end{tabular}


A Standard of care

Study

Wheeler et al.

Buchroithner et al.

Wen et al.

Sampson et al.

Cho et al.

Kong et al.

Wakabayashi et al.

Ursu et al.

Weller et al.

Random effects mode

Heterogeneity: $I^{2}=71 \%, \tau=0.08, \chi_{8}^{2}=27.21(p<0.01)$

C

Standard of care plus Immunotherapy

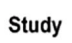

Wheeler et al.
Ursu et al.
Wen et al.
Buchroithner et al.
Weller et al.
Kong et al.
Wakabayashi et al.
Cho et al.
Sampson et al.

Sampson et al.

Random effects model

Heterogeneity: $I^{2}=75 \%, \tau=0.15, \chi_{8}^{2}=31.59(p<0.01)$

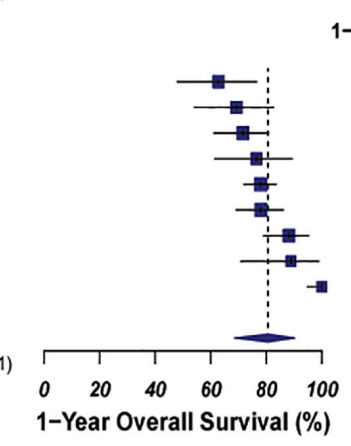

B

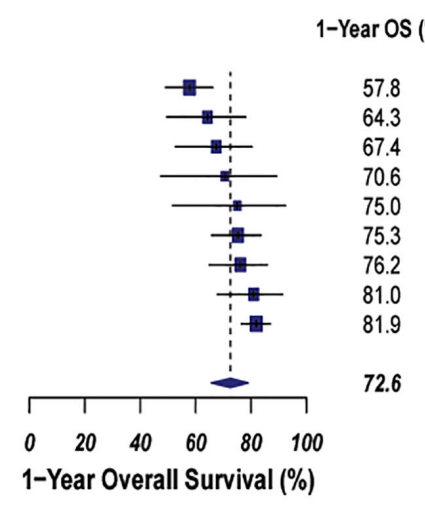

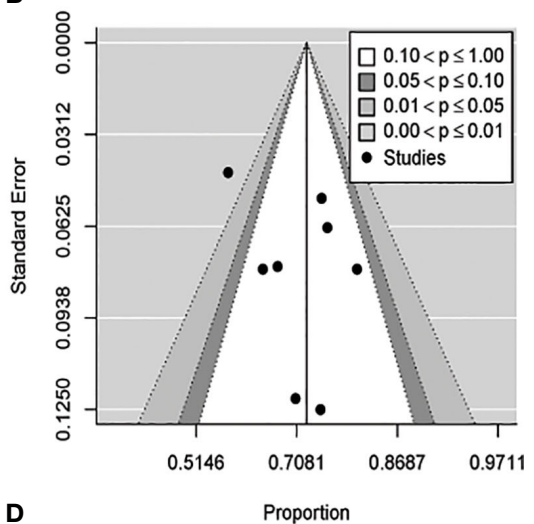

D

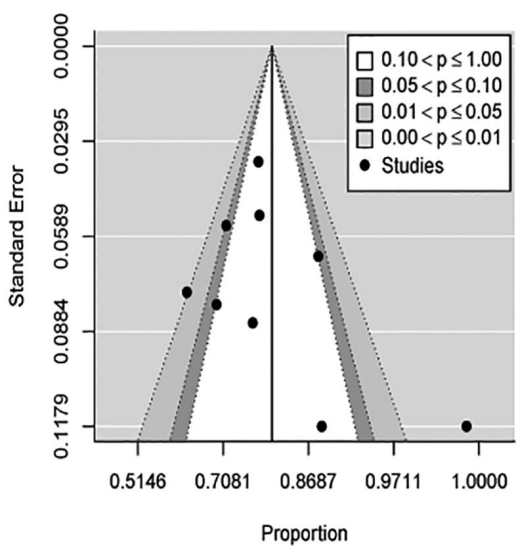

FIGURE 2 | Meta-analysis of 1-year OS in patients from all trials receiving standard of care or immunotherapy plus standard of care therapy. (A, B) 1-year OS forest and funnel plots of patients who received standard of care treatment [72.6\% (95\% Cl: 65.7\%-78.9\%, I2: 71\%)]. (C, D) 1-year OS forest and funnel plots of patients who received standard of care and immunotherapy treatment [80.6\% (95\% Cl: $68.6 \%-90.2 \%, 12: 75 \%)](p=0.15)$. Funnel plots showing no significant publication bias found in the present meta-analysis in both groups with p-values of 0.89 and 0.72 , in standard of care and immunotherapy treatment group respectively. In forest plots size of each square is proportional to its corresponding study's total sample size. The ends of the horizontal bars denote a 95\% Cl. The diamond gives the overall odds ratio for the combined results of all trials. The center denotes the odds ratio, and the extremities denote the $95 \% \mathrm{Cl}$.

weeks of completing radiation (39), and 1 to 2 months postoperatively (45).

There was significant variation among concomitant and maintenance therapy regiments that can directly influence OS and PFS of the individual studies. While most of the studies (6/ 10) used the standardized dose of TMZ and radiation during concomitant treatment (radiation at a dose of 60 Gy and TMZ at a dose of $75 \mathrm{mg} / \mathrm{m}^{2}$ ), two studies did not report doses $(41,44)$, and one study (45) used a higher TMZ dose $\left(100 \mathrm{mg} / \mathrm{m}^{2}\right)$. During the maintenance phase, TMZ was the most used drug, with some variabilities in dosage $\left(100 \mathrm{mg} / \mathrm{m}^{2}\right.$ to $\left.200 \mathrm{mg} / \mathrm{m}^{2}\right)$ and treatment length. Other agents used as maintenance treatment were: bevacizumab, nitrosoureas, irinotecan, tumor-treating fields, other chemotherapy (not defined), investigational drugs, tyrosine kinase inhibitors and check-point inhibitors $(42,44)$. In addition, there is significant variation in the radiation therapy practices for GBM around the word in terms of radiation dose and treatment field (51-53). Since the clinical trials included in our analysis originated in several different countries this variability is built into our model and is likely playing a critical role in the overall heterogeneity of the studies and overall outcome parameters being assessed.

Another known factor that significantly impacts patient's overall survival and PFS is the extent of resection (54, 55), which varied widely amongst the studies included in this metaanalysis. The variability in the total volume of tumor resected between studies is a limiting factor in evaluating the true response rate of immunotherapy. Patients were categorized under gross, subtotal, partial, and large resection, and in residual or non-residual disease. To make our analysis as consistent as possible, our calculations in the studies that considered those variables, were based on OS and PFS of total number of patients included without making distinctions in the surgical outcome. However, this almost certainly introduced some variability and noise into our data that could have been accounted for with a more consistently designed set of trials. Also, PFS assessment variability between studies has to be considered, since pseudo-progression is still a 
A

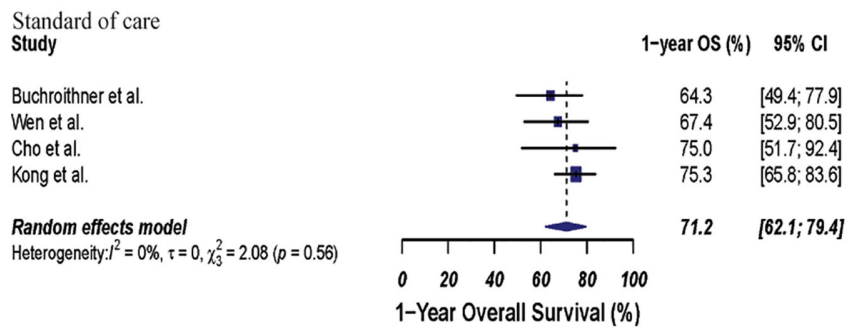

C

Standard of care plus Cellular vaccines

Study

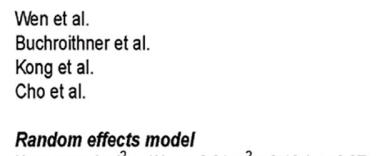

Random effects model
Heterogeneity: $l^{2}=4 \%, \tau<0.01, \chi_{3}^{2}=3.12(p=0.37)$

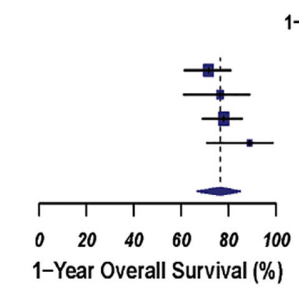

1-year OS (\%) $\quad 95 \% \mathrm{Cl}$

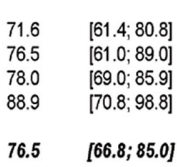

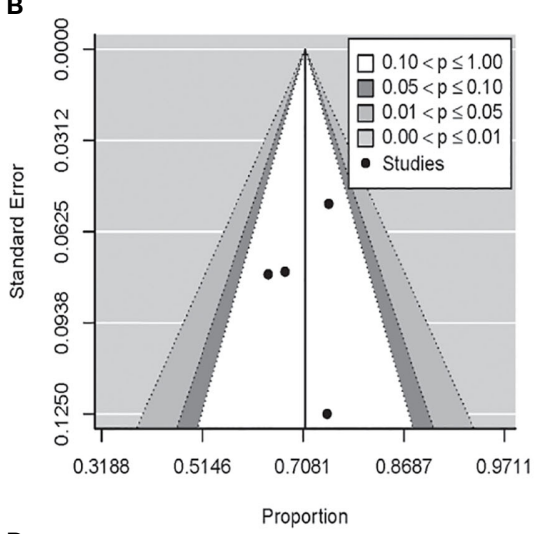

D

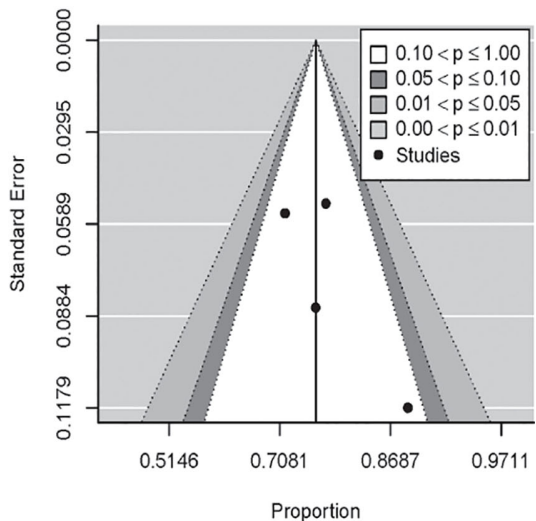

FIGURE 3 | Meta-analysis of 1-year OS in patients from trials receiving standard of care or cellular vaccine therapy plus standard of care therapy. (A, B) 1-year OS forest and funnel plots of patients who received standard of care treatment [71.2\% (95\% Cl: $\left.\left.62.1-79.4, \mathrm{I}^{2}=0 \%\right)\right]$. (C, D) 1 -year OS forest and funnel plots of patients who received standard of care and cellular vaccine treatment $\left[76.5 \%\left(95 \% \mathrm{Cl}: 66.8 \%-85 \%, \mathrm{I}^{2}=4 \%\right)(\mathrm{p}=0.21)\right]$. Funnel plots showing no significant publication bias found in the present meta-analysis in both groups with p-values of 0.82 and 0.36 , in standard of care and immunotherapy treatment group respectively. In forest plots size of each square is proportional to its corresponding study's total sample size. The ends of the horizontal bars denote a $95 \% \mathrm{Cl}$. The diamond gives the overall odds ratio for the combined results of all trials. The center denotes the odds ratio, and the extremities denote the $95 \% \mathrm{Cl}$.

controversial topic (56) that need to be addressed to ensure clear accountability of this parameter in response to immunotherapy. Although the Macdonald criteria for tumor response assessment was used by the majority of the studies, this classification has multiple limitations such as the presence of necrosis or residual changes secondary to tumor resection. As a result, a more comprehensive imaging criteria was defined for assessing response/progression by the Response Assessment in NeuroOncology (RANO) (57) and the immunotherapy response assessment for Neuro-oncology (iRANO). The RANO criteria is widely used in clinical trials in oncology for an accurate assessment of pseudo progression in response to temozolomide and radiotherapy in malignant gliomas during concomitant or maintenance regimens (58). RANO criteria does not suit properly the needs for response evaluation in patients treated with immune based therapies. Thus, the iRANO criteria was defined to assess clinical outcomes and tumor regression despite progression of the disease in the context of immunotherapy (59). It accounts for the differential mechanistic and imaging findings elicited by immunotherapy to the ones by chemoradiation; such as enhancing lesions outside the main radiation field and delayed therapeutic efficacy, that with other criteria would be classified as disease progression (60). iRANO defines disease progression when tumor persistence is registered in a specific period of time, after an initial radiographical evidence of tumor progression in response to immunotherapy (60).

Finally, although for the purposes of this analysis, we combined the included studies into the broad umbrella of "immunotherapy" it is useful to examine the specific therapies in more detail to clearly understand the clinical immunotherapy landscape.

\section{Cellular Vaccines}

Our analysis included three phase II clinical trials (Buchroithner et al. with 76 patients, Cho et al. with 34 patients and Wen et al. with 124 patients), that used dendritic cells, and one phase III trial (Kong et al. with 180 patients) that used cytokine-induced 
A

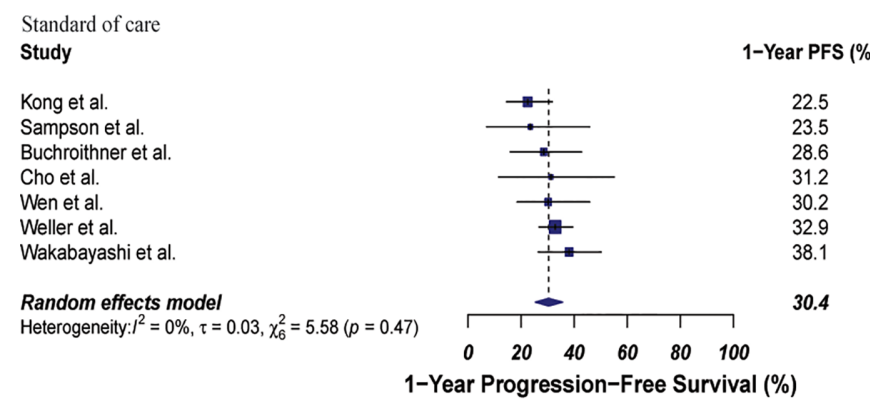

C

Standard of care plus Immunotherapy

Study

Buchroithner et al.

Kong et al.

Weller et al.

Wakabayashi et al.

Wen et al.

Cho et al.

Sampson et al.

Random effects model

Heterogeneity $: I^{2}=60 \%, \tau=0.08, \chi_{6}^{2}=15.13(p=0.02)$

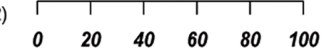

$1-$ Year Progression-Free Survival (\%)
B

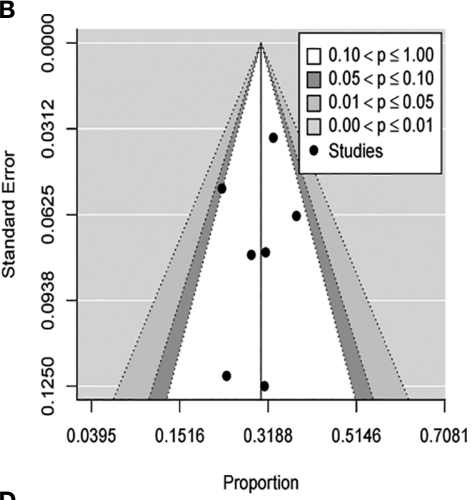

1-Year PFS (\%) $\quad 95 \% \mathrm{Cl}$

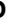

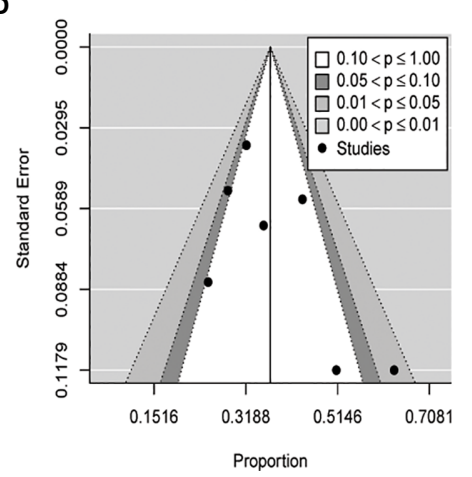

FIGURE 4 | Meta-analysis of 1-year PFS in patients from all trials receiving standard of care or immunotherapy plus standard of care therapy. (A, B) 1-year PFS forest and funnel plots of patients who received standard of care treatment [30.4\% (95\% Cl: 25.4-35.6; $\left.\left.\left.\right|^{2}=0 \%\right)\right]$. (C, D) 1 -year PFS forest and funnel plots of patients who received standard of care and immunotherapy treatment [37\% (95\% Cl: $\left.\left.26.4-48.2, I^{2}=60 \%\right)(p=0.17)\right]$. Funnel plots showing no significant publication bias found in the present meta-analysis in both groups with p-values of 0.63 and 0.13 in standard of care and immunotherapy treatment group respectively. In forest plots size of each square is proportional to its corresponding study's total sample size. The ends of the horizontal bars denote a $95 \%$ Cl. The diamond gives the overall odds ratio for the combined results of all trials. The center denotes the odds ratio, and the extremities denote the $95 \% \mathrm{Cl}$.

killer (CIK) cells with standard of care. Of these, the trial by Cho et al. showed the highest improvement in median and 1-year survival expectancy (median OS:15 vs 31.9 months, and 1-year OS: $75 \%$ vs $88.9 \%$, in control versus combined therapy, respectively). This can be attributed primarily to two distinct features of the trial: 1) the strategy of using personalized DCs vaccines, where a diverse group of individualized highly immunogenic peptides educating the DCs, could potentially elicit a better tumor clearance by the immune system and 2) the adjuvant treatment strategy used upon tumor recurrence, defined by tumor size increase $>20 \%$, which included repeated surgical-intervention, chemotherapy or boost gamma knife radiosurgery. In addition, a reinforced dose of vaccination (made from recurrent tumor tissue) was given to patients that underwent a second surgery (6 of 18 patients).

Of the four trials in this category the trial by Kong et al. was a phase III trial that showed very modest effect with an extension of 5.6 months in median OS and 3\% improvement at 1-year survival. The limited response in survival in this study could be mainly due to biodistribution of the cytokine induced lymphocytes and their ability to selectively home into the tumor microenvironment. Additionally, there was some variability in the timing of the administration of the cells which most likely influenced the overall outcome of the trial.

\section{Peptide Vaccines}

EGFR (epidermal growth factor receptor) overexpression is one of the most prevalent mutations in GBM (60\%) (61). $20 \%$ to $30 \%$ of these tumors, present a deletion of exons 2 to 7 in the EGFRvIII receptor (type III EGFR) (62). Sampson et al, phase II trial included 35 patients using EGFRvIII-targeted peptide vaccine and chemo-radiotherapy, showed an extension of approximately 9 months in median OS and PFS, extension of almost $30 \%$ at 1 -year survival and $40.1 \%$ at 1 -year PFS. However, in the phase III clinical trial that included 405 patients using this strategy, Weller et al, found no benefits in overall survival or PFS. (Median OS of 20 months in both groups, 1-year survival decreased by $4 \%$ with immunotherapy, improvement of 0.6 months in median PFS and 1\% decrease at 1-year PFS, with combined treatment). Benefits in the trial by Sampson et al. could be due to an enhanced humoral and cellular immune response rate produced by the vaccine elicited with dose intensified TMZ regiment $\left(100 \mathrm{mg} / \mathrm{m}^{2}\right.$ for first 21 days of 28 days cycle $)$ in comparison with standard dosing $\left(200 \mathrm{mg} / \mathrm{m}^{2}\right.$ for 
A

Standard of car

Study

Kong et al.

Buchroithner et al.

Cho et al.

Wen et al.

Random effects mode

Heterogeneity: $I^{2}=0 \%, \tau=0, \chi_{3}^{2}=1.34(p=0.72)$

$1-$ Year Progression-Free Survival (\%)

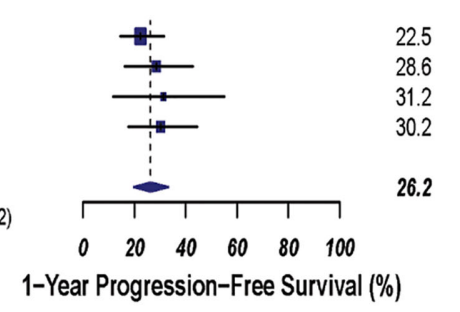

\section{1-year PFS (\%) $95 \% \mathrm{Cl}$}

$[14.5 ; 31.7]$

$[16.1 ; 43.0]$

$[11.6 ; 55.3]$

$[17.6 ; 44.6]$

[19.8; 33.3]

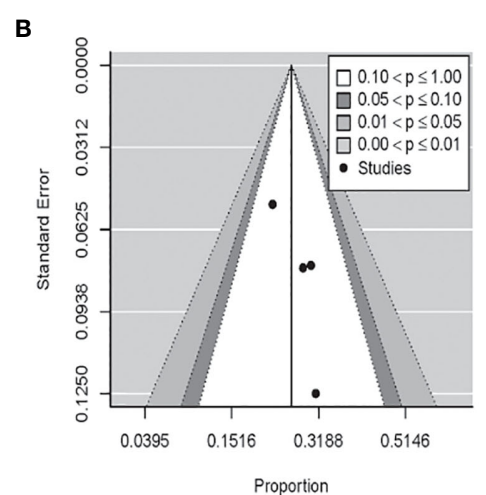

D

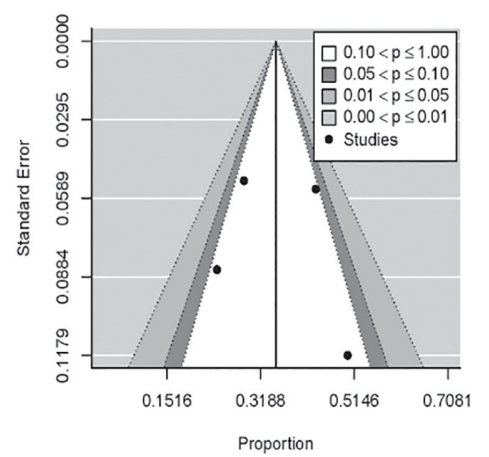

FIGURE 5 | Meta-analysis of 1-year PFS in patients from trials receiving standard of care or cellular vaccine therapy plus standard of care. (A, B) 1-year PFS forest and funnel plots of patients who received standard of care treatment [26.2\% (95\% Cl: 19.8-33.3, $\left.\left.\right|^{2}=0 \%\right)$. (C, D) 1-year PFS forest and funnel plots of patients who received standard of care and cellular vaccine treatment [35\% (95\% Cl: $\left.\left.18.2-53.9, \mathrm{I}^{2}=62 \%\right)(\mathrm{p}=0.19)\right]$. Funnel plots showing no significant publication bias found in the present meta-analysis in both groups $p=0.27$ and $p=0.73$, in standard of care and immunotherapy treatment group respectively. In forest plots size of each square is proportional to its corresponding study's total sample size. The ends of the horizontal bars denote a 95\% Cl. The diamond gives the overall odds ratio for the combined results of all trials. The center denotes the odds ratio, and the extremities denote the $95 \% \mathrm{Cl}$.

first 5 days of 28 days cycle), that was significant despite chemotherapy-induced lymphopenia. In comparison the phase III trial by Weller et al. used only the standard TMZ protocol and did not have the dose intensified arm. It is well described that the patient selection criteria and overall health status of the patients enrolled heavily weighs on the overall outcome of the patients in clinical trial (63). The majority of the patients included in the Sampson et al. trial had KPS score of 100 whereas majority of the patients in the Weller et al. trial had RPA class IV or higher, which most likely influenced the overall outcome. Most importantly the trial by Sampson et al. used historical control group which might not truly capture the complexity of the trial group and hence does not represent a true control arm.

\section{Other Immune-Based Therapies}

Other forms of immunotherapy clinical trials included: a) intracerebral administration of CpG ODN (44), b) intravenous IFN $\beta$ (47) and c) gene-mediated cytotoxic immunotherapy (aglatimagene besadenovec (AdV-tk), an adenoviral vector containing the herpes simplex virus thymidine kinase gene, followed by an antiherpetic prodrug such as valacyclovir) (41).
The phase II trial by Ursu et al. included 81 patients, showed no improvement in median and 1-year survival or median PFS with intracerebral administration of CpG ODN and chemoradiation. (median OS $\sim 18$ months and median PFS 9 months in both groups, and 1-year survival decreased by $10 \%$ ). The results of this trial again highlight the difficulties surrounding the issue of drug delivery and penetration in the context of GBM. In this trial CpG ODN was injected by needles in the resection cavity which restricted the amount of drug that penetrated beyond a small perimeter. Most local drug delivery studies report reliable penetration only few millimeters from the site of injection (50), whereas studies with convention enhanced delivery have reported a diffusion in centimeters $(64,65)$, still any tumor cells beyond that margin will not be affected by this treatment strategy.

The phase II clinical trial by Wakabayashi et al. included 122 patients and evaluated IFN $\beta$ in combination with standard of care for newly diagnosed GBMs and found an extended median OS of almost 4 months (1-year survival rate improved by 11\%) with combination therapy but a decrease in PFS by 1.6 months (1-year PFS decreased by $2.5 \%)$. IFN $\beta$ was used as a 
A

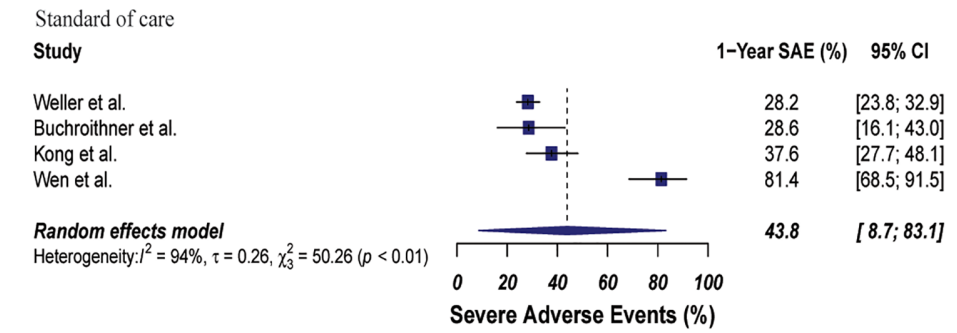

C

Standard of care plus Immunotherapy

Study

Weller et al.

Buchroithner et al.

Kong et al.

Wen et al.

Random effects model

Heterogeneity: $I^{2}=95 \%, \tau=0.17, \chi_{3}^{2}=64.25(p<0.01)$

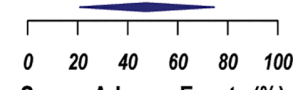

Severe Adverse Events (\%)
B

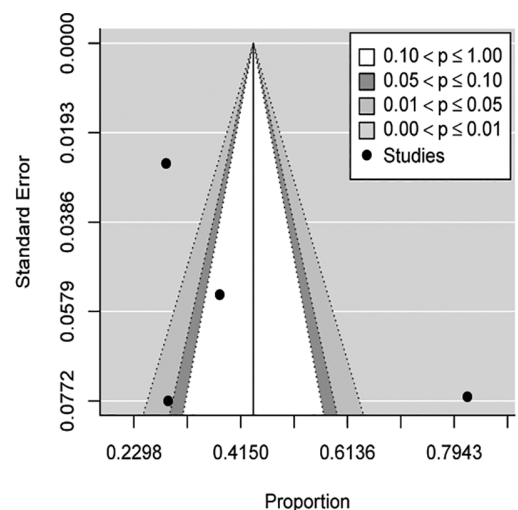

D

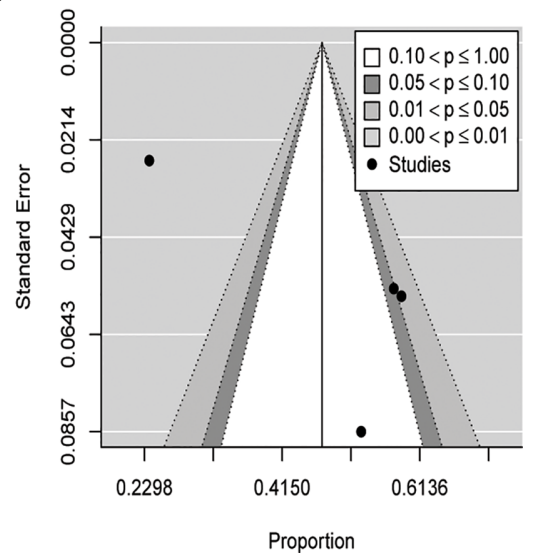

FIGURE 6 | Meta-analysis of SAEs grade 3 to 5 in patients from trials receiving standard of care or immunotherapy plus standard of care therapy. (A, B) SAEs forest and funnel plots of patients who received standard of care treatment [43.8\% (95\% Cl: 8.7-83.1, $\left.\left.{ }^{2}=94 \%\right)\right]$. (C, D) SAEs forest and funnel plots of patients who received standard of care and immunotherapy treatment $\left[47.3 \%\left(95 \% \mathrm{Cl}: 20.8-74.6, \mathrm{I}^{2}=95 \%\right)(p=0.81)\right]$. Funnel plots showing no significant publication bias found in the present meta-analysis in both groups $p=0.37$ and $p=0.22$, in standard of care and immunotherapy treatment group respectively. In forest plots size of each square is proportional to its corresponding study's total sample size. The ends of the horizontal bars denote a 95\% Cl. The diamond gives the overall odds ratio for the combined results of all trials. The center denotes the odds ratio, and the extremities denote the $95 \% \mathrm{Cl}$.

chemosensitizer that enhances the toxicity of chemotherapeutic agents such as TMZ. Thus, it is not surprising that the combination therapy arm had significantly higher rate of hematological as well as non-hematological toxicities. Higher toxicity also negatively impacted treatment compliance to the point that a high number of patients terminated the treatment protocol prematurely, which most likely played a role in the poor overall survival.

The Wheeler et al. phase II trial included 182 patients total and tested gene-mediated cytotoxic (GMC) immunotherapy in combination with standard of care. This trial did not yield survival benefits either, GBM data sub analysis showed 3month prolonged median OS and 1-year survival rate improved by $5 \%$ that were not statistically significant. Efficacy and biodistribution of the virus delivery by local injection in the resection cavity is limited by the previously outlined constrains of drug or biological agents penetration issues in the CNS microenvironment. In addition, virus particles induce prompt and effective anti-virus immune response which accelerates the clearance of virus further limiting its penetration in the tumor microenvironment (66). If the issue of immune mediated virus clearance is not weighted in properly into the timing of administration of the activating pro-drug there will be no effective immune response. Extent of resection is also important when assessing the likelihood of overall success of immunotherapy since immunosuppressive features such as expression of PD-L1, presence of regulatory cells etc. in the residual tumors decreases the overall efficacy of the immunotherapy (67).

In summary, upon closer evaluation of the individual immunotherapies across the trials analyzed in this study, it becomes clear that there is a large amount of variability in patient response within the trials and across the trials. This highlights the often-seen tail phenomenon of GBM patients in immunotherapy trials where there are small groups of patients who do respond and do while even if the majority of patients in cohort may not benefit resulting in an overall negative trial (16). This data points toward the need for better design of 
A

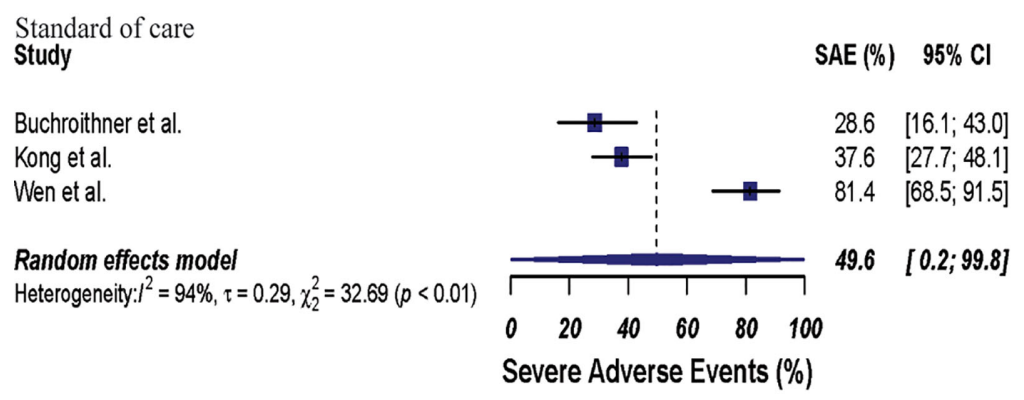

C Standard of care plus Cellular vaccines Study

Buchroithner et al.
Kong et al.
Wen et al.
Random effects model
Heterogeneity: $I^{2}=0 \%, \tau=0, \chi_{2}^{2}=0.33(p=0.85)$

Buchroithner et al.

Kong et al.

Random effects mode Heterogeneity: $l^{2}=0 \%, \tau=0, x_{2}^{2}=0.33(p=0.85)$

SAE $(\%) \quad 95 \% \mathrm{Cl}$
B
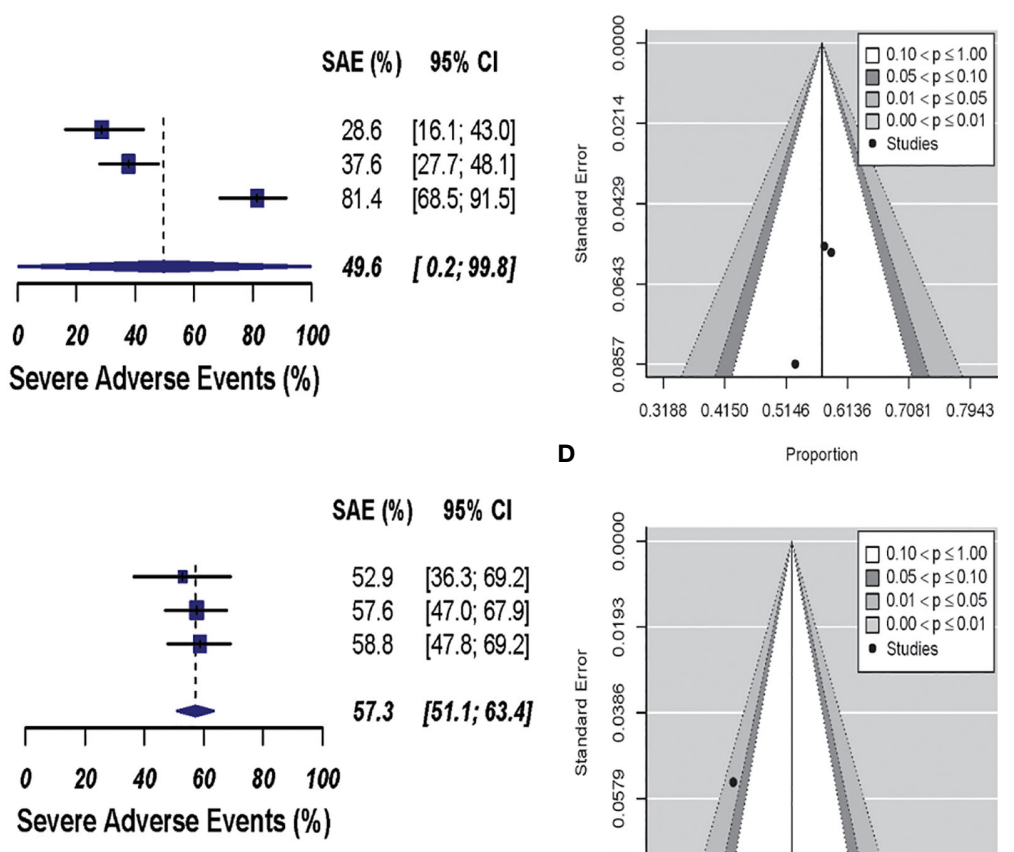

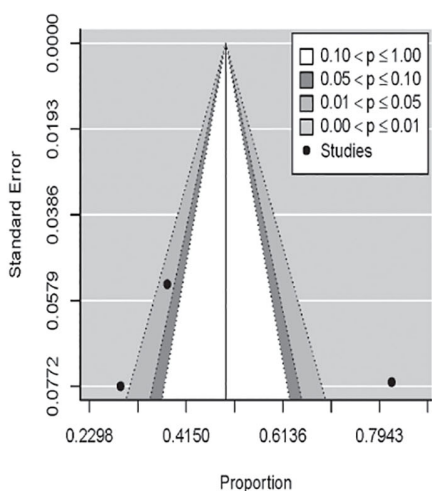

FIGURE 7 | Meta-analysis of SAEs grade 3 to 5 in patients from trials receiving standard of care or cellular vaccine therapy plus standard of care. (A, B) SAEs forest and funnel plots of patients who received standard of care treatment [49.6\% (95\% Cl: 0.2-99.8, $\left.\left.\mathrm{I}^{2}=94 \%\right)\right]$. (C, D) SAEs forest and funnel plots of patients who received standard of care plus cellular vaccine treatment $\left[57.3 \%\left(95 \% \mathrm{Cl}: 51.1-63.4, \mathrm{I}^{2}=0 \%\right)(\mathrm{p}=0.68)\right]$. Funnel plots showing no significant publication bias in both groups with p-values of 0.78 and 0.19 in standard of care and immunotherapy treatment group respectively. In forest plots size of each square is proportional to its corresponding study's total sample size. The ends of the horizontal bars denote a 95\% Cl. The diamond gives the overall odds ratio for the combined results of all trials. The center denotes the odds ratio, and the extremities denote the $95 \% \mathrm{Cl}$.

TABLE 3 | Summarized results for 1-year OS and PFS, and SAEs in standard of care and standard of care and immunotherapy groups, and for trials that used cellular vaccines only.

\begin{tabular}{lccc}
\hline Group & Outcome & Wald Test & Peter's Test \\
\hline Control & 1y OS & Ref & 0.89 \\
Combined & 1y OS & 0.15 & 0.72 \\
Control (Vaccine Only) & 1y OS & Ref & 0.82 \\
Combined (Vaccine Only) & 1y OS & 0.21 & 0.36 \\
Control & 1y PFS & Ref & 0.63 \\
Combined & 1y PFS & 0.17 & 0.13 \\
Control (Vaccine Only) & 1y PFS & Ref & 0.27 \\
Combined Vaccine Only) & 1y PFS & 0.19 & 0.73 \\
Control & SAE & Ref & 0.37 \\
Combined & SAE & 0.81 & 0.22 \\
Control (Vaccine Only) & SAE & Ref & 0.78 \\
Combined (Vaccine Only) & SAE & 0.68 & 0.19 \\
\hline
\end{tabular}

immunotherapy clinical trials that include potential responders using synergistic combination therapy that boosts the overall function of the immune system in addition to tumor specific immune response.

\section{Severe Adverse Events in Immunotherapy}

SAEs in clinical trials are considered as complications/toxicity, morbidity or mortality as a result of a tested treatment (68). They can be symptomatic (reported by the patient) or asymptomatic (detected during a physical examination, laboratory results or imaging reports) (69). Grade 1 and 2 events are mild or moderate, or even asymptomatic symptoms that can be managed with outpatient medication. Grade 3 events are severe non-immediately-life threatening symptoms that can be controlled usually during inpatient treatment or prolonged hospitalization (parental administration of drugs or surgical intervention). Grade 4 events put the life of the person at risk, and can result in disabilities and organ dysfunctions, whereas grade 5 events are deadly $(69,70)$.

There was significant heterogeneity in the SAE reporting criteria used by each of the clinical trials included in this metaanalysis. Criteria used for the grading and defining grade 3 to 5 SAEs in the studies included in this analysis were the National Cancer Institute (NCI) Common Terminology Criteria for Adverse Events (CTCAE) version 3.0 by Wheeler et al, Wakabayashi et al, and by Kong et al, and version 4.0 by 
Weller et al. The precursor of this classification, the NCI Common Toxicity Criteria (CTC) version 2.0 was used by Sampson et al, version 3.0 by Ursu, version 4.0 by Buchroithner, and 4.03 by Wen. Cho's trial did not specify the classification used. Analysis of SAEs grade 3 to 5 in Cho, Sampson, Ursu, Wakabayashi and Wheeler's trials were not possible due to the presentation of the data. (ie, grades 2 and 3 events reported combined, events non-separated by grade, and events reported separately during concomitant and/or maintenance treatment).

We only used four out of the nine studies for the grade 3 to 5 SAE analysis $(40,42,46,48)$. Our analysis showed an increased occurrence of grade 3 to 5 SAEs associated with immunotherapy in combination with chemo-radiation compared to chemo and radiation but the effect failed to reach statistical significance. Although some of these events may be expected due to the immune nature of the therapies and the known effects of chemoradiation, the majority of these were severe nonimmediately-life threatening SAEs controlled with inpatient medication or hospitalization. The only two deadly events found with our analysis was with the immunotherapy $\mathrm{CpG}$ in the study by Ursu et al. (secondary to reactivation of hepatitis B infection) and the peptide vaccine in Sampson's trial (due to pulmonary embolism). Among immunotherapy approaches, the most common SAEs were: headache, nausea, vomiting, seizures, constipation, diarrhea, weakness, anorexia, pyrexia, increase transaminases, increase lipases, increase intracranial pressure, and rash/allergic reactions. Hematological toxicities frequently seen after immunotherapy and standard of care were: lymphopenia, thrombocytopenia and neutropenia (For grading criteria of the most common grade 3 to 5 SAEs found among trials go to Supplementary Table 9).

Pneumonia and acute-renal failure were specifically described in one trial using cellular vaccines (46). Peptide vaccines were specifically linked with brain edema, and one deadly event due to pulmonary thromboembolism (48). CpG ODN and chemoradiation was related with post-surgical hematoma, seizures (probably secondary to the intracerebral administration of the agent), and with one death related with reactivation of hepatitis $B$ infection (although a full analysis of SAEs was not possible due to the format used for data presentation). Gene-mediated cytotoxicity therapy was related with hemiparesis (motor neuropathy), speech impairment, insomnia, and wound complication (specific analysis of SAEs 3 to 5 was not possible due to how the data was presented).

Taken together, this evidence demonstrates that although adverse events grade 3 to 5 are more frequent in the immunotherapy and chemo-radiation treatment when compared with chemo-radiation only, they are mostly nondeadly toxicities that can be managed during an inpatient encounter or hospitalization. Importantly, our findings are in accordance with the data described in the retrospective study of 22 trials done by Magee and colleagues in 2020, where the risk of an adverse event grade 3 or higher was increased in the immunotherapy arm compared with the chemotherapy arm alone for solid tumors (71). Nonetheless, our data show that this trend in increased toxicity in immunotherapy was not statistically significant.

\section{STRENGTHS AND LIMITATIONS}

The strength of our study lies in the strict inclusion and exclusion criteria used for article selection. We used a clearly defined list formed by several characteristics allowing us to compare control versus combined therapy in newly diagnosed GBM patients. This eliminated the potential of patients having received prior treatment. Additionally, we included phase II and III clinical trials that evaluated survival benefits (OS and PFS), as well as toxicity (SAEs) secondary to treatment. By doing so, we were able to perform a more reliable comparison of the results in the control and combined groups for each study. Moreover, we attempted to reduce heterogeneity by excluding trials that were not specifically described as phase II or III, even if they described OS, PFS, or adverse events related with immunotherapy.

Our study also has significant limitations, with inherent variabilities between studies, such as sample size and different statistical methods (HR, CIs) as well as variable modalities of immunotherapies, radiation and chemotherapy doses. Also, in GBM the response to chemo-radiotherapy is significantly affected by the genetic makeup of the tumor (72) and through analysis of biological confounding variables, such as IDH mutations, 1p19q co-deletion, MGMT status etc, could not be done since many trials did not include this information. Importantly, the lack of similarity in treatment modalities and schemes used in these studies limits a truly fair comparison of the possible benefit of immunotherapy. Another limitation in our study is the selection of clinical trials phase II and III, that might bias the results due to the often benefit seen in clinical studies phase II, that do not demonstrate benefits when tested in multiple centers in larger cohorts during phase III trials. Our intention is not to overestimate (or vice versa) the effect of immunotherapy in GBM, but to demonstrate that more clinical trials accounting for dependent and independent-patient variables are needed to truly understand the full potential of immunotherapy in combination with current standard of care.

\section{CONCLUSION}

In summary, our results demonstrated that the combination of immunotherapy with standard of care chemotherapy and radiation produced no significant survival benefit in patients. Furthermore, the combination was not significantly associated with an increased incidence of grade 3 to 5 SAEs, despite the observed trend. Most of these SAEs were successfully managed clinically, which allow us to conclude that the integration of immunotherapy into the standard of care for GBM is relatively safe. We believe, standardization of clinical trials in regard to immunotherapy and chemo-radiation treatment schemes for GBM treatment is necessary for a more accurate comparison 
and analysis of these combined treatments and is warranted to fully explore the potential benefits of this therapeutic combination.
All authors contributed to the article and approved the submitted version.

\section{DATA AVAILABILITY STATEMENT}

The original contributions presented in the study are included in the article/Supplementary Material. Further inquiries can be directed to the corresponding author.

\section{AUTHOR CONTRIBUTIONS}

ML-V, JS, MD, and HR-G wrote the manuscript. ML-V, KB, HR$\mathrm{G}$, and JS collected the data. EJL, MP, and RC analyzed the data.

\section{REFERENCES}

1. Jang HS, Shin WJ, Lee JE, Do JT. Cpg and Non-CpG Methylation in Epigenetic Gene Regulation and Brain Function. Genes (Basel) (2017) 8:148. doi: 10.3390/genes8060148

2. Davis ME. Glioblastoma: Overview of Disease and Treatment. Clin J Oncol Nurs (2016) 20:S2-8. doi: 10.1188/16.CJON.S1.2-8

3. Nabors LB, Portnow J, Ahluwalia M, Baehring J, Brem H, Brem S, et al. Central Nervous System Cancers, Version 3.2020, NCCN Clinical Practice Guidelines in Oncology. J Natl Compr Canc Netw (2020) 18:1537-70. doi: 10.6004/jnccn.2020.0052

4. Stupp R, Mason WP, van den Bent MJ, Weller M, Fisher B, Taphoorn MJB, et al. Radiotherapy Plus Concomitant and Adjuvant Temozolomide for Glioblastoma. N Engl J Med (2005) 352:987-96. doi: 10.1056/NEJMoa043330

5. Lara-Velazquez M, Al-Kharboosh R, Jeanneret S, Vazquez-Ramos C, Mahato D, Tavanaiepour D, et al. Advances in Brain Tumor Surgery for Glioblastoma in Adults. Brain Sci (2017) 7(10):1100-8. doi: 10.3390/brainsci7120166

6. Fernandes C, Costa A, Osório L, Costa Lago R, Linhares P, Carvalho B, et al. Current Standards of Care in Glioblastoma Therapy. In: S De Vleeschouwer, editor. Glioblastoma. Brisbane (AU: Codon Publications Copyright: The Authors (2017).

7. Stupp R, Taillibert S, Kanner AA, Kesari S, Steinberg DM, Toms SA, et al. Maintenance Therapy With Tumor-Treating Fields Plus Temozolomide vs Temozolomide Alone for Glioblastoma: A Randomized Clinical Trial. JAMA (2015) 314:2535-43. doi: 10.1001/jama.2015.16669

8. Mallick S, Benson R, Hakim A, Rath GK. Management of Glioblastoma After Recurrence: A Changing Paradigm. J Egypt Natl Canc Inst (2016) 28:199-210. doi: 10.1016/j.jnci.2016.07.001

9. Gandhi L, Rodriguez-Abreu D, Gadgeel S, Esteban E, Felip E, De Angelis F, et al. Pembrolizumab Plus Chemotherapy in Metastatic non-Small-Cell Lung Cancer. N Engl J Med (2018) 378:2078-92. doi: 10.1056/NEJMoa1801005

10. Lehrer EJ, McGee HM, Peterson JL, Vallow L, Ruiz-Garcia HG, Zaorsky N, et al. Stereotactic Radiosurgery and Immune Checkpoint Inhibitors in the Management of Brain Metastases. Int J Mol Sci (2018) 19(10):3054. doi: 10.3390/ijms19103054

11. Lehrer EJ, McGee HM, Sheehan JP, Trifiletti DM. Integration of ImmunoOncology With Stereotactic Radiosurgery in the Management of Brain Metastases. J Neurooncol (2021) 151:75-84. doi: 10.1007/s11060-020-03427-6

12. Lehrer EJ, Peterson J, Brown PD, Sheehan JP, Quiñones-Hinojosa A, Zaorsky NG, et al. Treatment of Brain Metastases With Stereotactic Radiosurgery and Immune Checkpoint Inhibitors: An International Meta-Analysis of Individual Patient Data. Radiother Oncol (2019) 130:104-12. doi: 10.1016/ j.radonc.2018.08.025

13. Reck M, Rodriguez-Abreu D, Robinson AG, Hui R, Csőszi T, Fülöp A, et al. Pembrolizumab Versus Chemotherapy for PD-L1-Positive non-Small-Cell Lung Cancer. N Engl J Med (2016) 375:1823-33. doi: 10.1056/NEJMoal606774

14. Tan AC, Ashley DM, López GY, Malinzak M, Friedman HS, Khasraw M, et al. Management of glioblastoma: State of the art and future directions. CA Cancer J Clin (2020) 70:299-312. doi: 10.3322/caac.21613

\section{FUNDING}

This work was supported by the NIH K08NS092895 grant (MD).

\section{SUPPLEMENTARY MATERIAL}

The Supplementary Material for this article can be found online at: https://www.frontiersin.org/articles/10.3389/fonc.2021. 662302/full\#supplementary-material

15. Kamiya-Matsuoka C, Gilbert MR. Treating Recurrent Glioblastoma: An Update. CNS Oncol (2015) 4:91-104. doi: 10.2217/cns.14.55

16. McGranahan T, Therkelsen KE, Ahmad S, Nagpal S. Current State of Immunotherapy for Treatment of Glioblastoma. Curr Treat Options Oncol (2019) 20:24. doi: 10.1007/s11864-019-0619-4

17. Wahid B, Ali A, Rafique S, Waqar M, ad Wasim M, Wahid K, et al. An Overview of Cancer Immunotherapeutic Strategies. Immunotherapy (2018) 10:999-1010. doi: 10.2217/imt-2018-0002

18. Yang Y. Cancer Immunotherapy: Harnessing the Immune System to Battle Cancer. J Clin Invest (2015) 125:3335-7. doi: 10.1172/JCI83871

19. Johanns TM, Bowman-Kirigin JA, Liu C, Dunn GP. Targeting Neoantigens in Glioblastoma: An Overview of Cancer Immunogenomics and Translational Implications. Neurosurgery (2017) 64:165-76. doi: 10.1093/neuros/nyx321

20. Raucher D. Tumor Targeting Peptides: Novel Therapeutic Strategies in Glioblastoma. Curr Opin Pharmacol (2019) 47:14-9. doi: 10.1016/ j.coph.2019.01.006

21. Koury J, Lucero M, Cato C, Chang L, Geiger J, Henry H, et al. Immunotherapies: Exploiting the Immune System for Cancer Treatment. J Immunol Res (2018) 2018:9585614. doi: 10.1155/2018/9585614

22. Waldman AD, Fritz JM, Lenardo MJ. A Guide to Cancer Immunotherapy: From T Cell Basic Science to Clinical Practice. Nat Rev Immunol (2020) 20:651-68. doi: 10.1038/s41577-020-0306-5

23. Al-Kharboosh R, ReFaey K, Lara-Velazquez M, Grewal SS, Imitola J, Quiñones-Hinojosa A. Inflammatory Mediators in Glioma Microenvironment Play a Dual Role in Gliomagenesis and Mesenchymal Stem Cell Homing: Implication for Cellular Therapy. Mayo Clin Proc Innov Qual Outcomes (2020) 4:443-59. doi: 10.1016/j.mayocpiqo.2020.04.006

24. Choi BD, Maus MV, June CH, Sampson JH. Immunotherapy for Glioblastoma: Adoptive T-cell Strategies. Clin Cancer Res (2019) 25:2042-8. doi: 10.1158/1078-0432.CCR-18-1625

25. Sampson JH, Maus MV, June CH. Immunotherapy for Brain Tumors. J Clin Oncol (2017) 35:2450-6. doi: 10.1200/JCO.2017.72.8089

26. Akhavan D, Alizadeh D, Wang D, Weist MR, Shepphird JK, Brown CE. Car T Cells for Brain Tumors: Lessons Learned and Road Ahead. Immunol Rev (2019) 290:60-84. doi: 10.1111/imr.12773

27. Weenink B, French PJ, Sillevis Smitt PAE, Debets R, Geurts M. Immunotherapy in Glioblastoma: Current Shortcomings and Future Perspectives. Cancers (Basel) (2020) 12:1-20. doi: 10.3390/cancers12030751

28. Farber SH, Elsamadicy AA, Atik AF, Suryadevara CM, Chongsathidkiet P, Fecci PE, et al. The Safety of Available Immunotherapy for the Treatment of Glioblastoma. Expert Opin Drug Saf (2017) 16:277-87. doi: 10.1080/ 14740338.2017.1273898

29. Available at: https://www.targetedonc.com/view/upfront-nivolumab-notadditive-in-phase-iii-trial-of-mgmtmethylated-gbm.

30. Available at: https://clinicaltrials.gov/ct2/show/results/NCT02667587?term= NCT02667587\&draw $=2 \&$ rank $=1$.

31. Available at: https://news.bms.com/news/details/2019/Bristol-Myers-SquibbAnnounces-Phase-3-CheckMate-498-Study-Did-Not-Meet-PrimaryEndpoint-of-Overall-Survival-with-Opdivo-nivolumab-Plus-Radiation-in- 
Patients-with-Newly-Diagnosed-MGMT-Unmethylated-GlioblastomaMultiforme/default.aspx.

32. Available at: https://clinicaltrials.gov/ct2/show/NCT02617589?term= NCT02617589\&draw $=2 \&$ rank $=1$.

33. Available at: https://clinicaltrials.gov/ct2/show/NCT04396860.

34. Moher D, Liberati A, Tetzlaff J, Altman D. Preferred Reporting Items for Systematic Reviews and Meta-Analyses: The PRISMA Statement. PloS Med (2009) 6:e1000097. doi: 10.1371/journal.pmed.1000097

35. Stroup DF, Berlin JA, Morton SC, Olkin I, Williamson GD, Rennie D, et al. Meta-Analysis of Observational Studies in Epidemiology: A Proposal for Reporting. Meta-analysis Of Observational Stud Epidemiol (MOOSE) Group JAMA (2000) 283:2008-12. doi: 10.1001/jama.283.15.2008

36. Team R. Rstudio: Integrated Development Environment for R. Boston, MA: RStudio, PBC (2015). Available at: http://www.rstudio.com/.

37. Lehrer EJ, Singh R, Wang M, Chinchilli VM, Trifiletti DM, Ost P, et al. Safety and Survival Rates Associated With Ablative Stereotactic Radiotherapy for Patients With Oligometastatic Cancer: A Systematic Review and MetaAnalysis. JAMA Oncol (2021) 7:92-106. doi: 10.1001/jamaoncol.2020.6146

38. Minozzi S, Cinquini M, Gianola S, Gonzalez-Lorenzo M, Banzi R. The Revised Cochrane Risk of Bias Tool for Randomized Trials (Rob 2) Showed Low Interrater Reliability and Challenges in its Application. J Clin Epidemiol (2020) 126:37-44. doi: 10.1016/j.jclinepi.2020.06.015

39. Sampson JH, Aldape KD, Archer GE, Coan A, Desjardins A, Friedman AH, et al. Greater Chemotherapy-Induced Lymphopenia Enhances TumorSpecific Immune Responses That Eliminate EGFRvIII-expressing Tumor Cells in Patients With Glioblastoma. Neuro-Oncology (2010) 13:324-33. doi: 10.1093/neuonc/noq157

40. Wen PY, Reardon DA, Armstrong TS, Phuphanich S, Aiken RD, Landolfi JC, et al. A Randomized Double-Blind Placebo-Controlled Phase II Trial of Dendritic Cell Vaccine Ict-107 in Newly Diagnosed Patients With Glioblastoma. Clin Cancer Res (2019) 25:5799-807. doi: 10.1158/10780432.CCR-19-0261

41. Wheeler LA, Manzanera AG, Bell SD, Cavaliere R, McGregor JM, Grecula JC, et al. Phase II Multicenter Study of Gene-Mediated Cytotoxic Immunotherapy as Adjuvant to Surgical Resection for Newly Diagnosed Malignant Glioma. Neuro-Oncology (2016) 18:1137-45. doi: 10.1093/neuonc/now002

42. Buchroithner J, Erhart F, Pichler J, Widhalm G, Preusser M, Stockhammer G, et al. Audencel Immunotherapy Based on Dendritic Cells Has No Effect on Overall and Progression-Free Survival in Newly Diagnosed Glioblastoma: A Phase II Randomized Trial. Cancers (Basel) (2018) 10(10):372. doi: 10.3390/ cancers 10100372

43. Stupp R, Hegi ME, Gorlia T, Erridge SC, Perry J, Hong Y, et al. Cilengitide Combined With Standard Treatment for Patients With Newly Diagnosed Glioblastoma With Methylated MGMT Promoter (CENTRIC EORTC 2607122072 Study): A Multicentre, Randomised, Open-Label, Phase 3 Trial. Lancet Oncol (2014) 15:1100-8. doi: 10.1016/S1470-2045(14)70379-1

44. Ursu R, Carpentier A, Metellus P, Chinot O, Lambert J, Carpentier AF, et al. Intracerebral Injection of $\mathrm{CpG}$ Oligonucleotide for Patients With De Novo Glioblastoma-a Phase II Multicentric, Randomised Study. Eur J Cancer (2017) 73:30-7. doi: 10.1016/j.ejca.2016.12.003

45. Cho D-Y, Yang W-K, Lee H-C, MeiHsu D, LinLin H, Zong Lin S, et al. Adjuvant Immunotherapy With Whole-Cell Lysate Dendritic Cells Vaccine for Glioblastoma Multiforme: A Phase II Clinical Trial. World Neurosurg (2012) 77:736-44. doi: 10.1016/j.wneu.2011.08.020

46. Kong DS, Nam DH, Kang SH, Lee JW, Chang JH, Kim J, et al. Phase III Randomized Trial of Autologous Cytokine-Induced Killer Cell Immunotherapy for Newly Diagnosed Glioblastoma in Korea. Oncotarget (2017) 8:7003-13. doi: 10.18632/oncotarget.12273

47. Wakabayashi T, Natsume A, Mizusawa J, Katayama H, Fukuda H, Sumi M, et al. Jcog0911 INTEGRA Study: A Randomized Screening Phase II Trial of Interferon $\beta$ Plus Temozolomide in Comparison With Temozolomide Alone for Newly Diagnosed Glioblastoma. J Neurooncol (2018) 138:627-36. doi: 10.1007/s11060-018-2831-7

48. Weller M, Butowski N, Tran DD, Recht LD, Lim M, Hirte H, et al. Rindopepimut With Temozolomide for Patients With Newly Diagnosed, EGFRvIII-expressing Glioblastoma (ACT IV): A Randomised, DoubleBlind, International Phase 3 Trial. Lancet Oncol (2017) 18:1373-85. doi: 10.1016/S1470-2045(17)30517-X
49. Chinnaiyan P, Won M, Wen PY, Rojiani AM, Werner-Wasik M, Shih HA, et al. A Randomized Phase II Study of Everolimus in Combination With Chemoradiation in Newly Diagnosed Glioblastoma: Results of NRG Oncology RTOG 0913. Neuro Oncol (2018) 20:666-73. doi: 10.1093/ neuonc/nox209

50. Lee EQ, Kaley TJ, Duda DG, Schiff D, Lassman AB, Wong ET, et al. A Multicenter, Phase II, Randomized, Noncomparative Clinical Trial of Radiation and Temozolomide With or Without Vandetanib in Newly Diagnosed Glioblastoma Patients. Clin Cancer Res (2015) 21:3610-8. doi: 10.1158/1078-0432.CCR-14-3220

51. Cabrera AR, Kirkpatrick JP, Fiveash JB, Chakravarti A, Wen PY, Chang E, et al. Radiation Therapy for Glioblastoma: Executive Summary of an American Society for Radiation Oncology Evidence-Based Clinical Practice Guideline. Pract Radiat Oncol (2016) 6:217-25. doi: 10.1016/j.prro. 2016.03.007

52. Palmer JD, Gamez ME, Ranta K, Ruiz-Garcia H, Peterson JL, Blakaj DM, et al. Radiation Therapy Strategies for Skull-Base Malignancies. J Neurooncol (2020) 150:445-62. doi: 10.1007/s11060-020-03569-7

53. Trifiletti DM, Ruiz-Garcia H, Quinones-Hinojosa A, Ramakrishna R, Sheehan JP. The Evolution of Stereotactic Radiosurgery in Neurosurgical Practice. J Neurooncol (2021) 151:451-9. doi: 10.1007/s11060-020-03392-0

54. ALA-Glioma Study Group. Extent of Resection and Survival in Glioblastoma Multiforme: Identification of and Adjustment for Bias. Neurosurgery (2008) 62:564-76; discussion -76. doi: 10.1227/01.neu.0000317304.31579.17

55. Suarez-Meade P, Marenco-Hillembrand L, Prevatt C, Murguia-Fuentes R, Mohamed A, Alsaeed T, et al. Awake vs. Asleep Motor Mapping for Glioma Resection: A Systematic Review and Meta-Analysis. Acta Neurochir (Wien) (2020) 162:1709-20. doi: 10.1007/s00701-020-04357-y

56. Ellingson BM, Chung C, Pope WB, Boxerman JL, Kaufmann TJ. Pseudoprogression, Radionecrosis, Inflammation or True Tumor Progression? Challenges Associated With Glioblastoma Response Assessment in an Evolving Therapeutic Landscape. J Neurooncol (2017) 134:495-504. doi: 10.1007/s11060-017-2375-2

57. Vogelbaum MA, Jost S, Aghi MK, Heimberger AB, Sampson JH, Wen PY, et al. Application of Novel Response/Progression Measures for Surgically Delivered Therapies for Gliomas: Response Assessment in Neuro-Oncology (Rano) Working Group. Neurosurgery (2012) 70:234-44. doi: 10.1227/ NEU.0b013e318223f5a7

58. Chukwueke UN, Wen PY. Use of the Response Assessment in NeuroOncology (RANO) Criteria in Clinical Trials and Clinical Practice. CNS Oncol (2019) 8:CNS28-CNS. doi: 10.2217/cns-2018-0007

59. Okada H, Downey KM, Reardon DA. Chapter 59 - Immunotherapy Response Assessment in Neuro-Oncology (Irano). In: HB Newton, editor. Handbook of Brain Tumor Chemotherapy, Molecular Therapeutics, and Immunotherapy, 2nd ed. United States: Academic Press (2018). p. 761-6. doi: 10.1016/B978-012-812100-9.00060-7

60. Okada H, Weller M, Huang R, Finocchiaro G, Gilbert MR, Wick W, et al. Immunotherapy Response Assessment in Neuro-Oncology: A Report of the RANO Working Group. Lancet Oncol (2015) 16:e534-42. doi: 10.1016/S14702045(15)00088-1

61. Moscatello DK, Ramirez G, Wong AJ. A Naturally Occurring Mutant Human Epidermal Growth Factor Receptor as a Target for Peptide Vaccine Immunotherapy of Tumors. Cancer Res (1997) 57:1419-24.

62. Heimberger AB, Suki D, Yang D, Shi W, Aldape K. The Natural History of EGFR and EGFRvIII in Glioblastoma Patients. J Transl Med (2005) 3:38. doi: 10.1186/1479-5876-3-38

63. Lawrence W Jr. Patient Selection for Clinical Trials. Risks Versus Benefits and Quality of Life Issues. Cancer (1993) 72:2798-800. doi: 10.1002/1097-0142 (19931101)72:9+<2798::AID-CNCR2820721504>3.0.CO;2-\#

64. Morrison PF, Laske DW, Bobo H, Oldfield EH, Dedrick RL. High-Flow Microinfusion: Tissue Penetration and Pharmacodynamics. Am J Physiol (1994) 266:R292-305. doi: 10.1152/ajpregu.1994.266.1.R292

65. Fiandaca MS, Berger MS, Bankiewicz KS. The Use of Convection-Enhanced Delivery With Liposomal Toxins in Neurooncology. Toxins (Basel) (2011) 3:369-97. doi: 10.3390/toxins3040369

66. Hulou MM, Cho C-F, Chiocca EA, Bjerkvig R. Chapter 11 - Experimental therapies: gene therapies and oncolytic viruses. Handb Clin Neurol (2016) 134:183-97. doi: 10.1016/B978-0-12-802997-8.00011-6 
67. Bakos O, Lawson C, Rouleau S, Tai L-H. Combining Surgery and Immunotherapy: Turning an Immunosuppressive Effect Into a Therapeutic Opportunity. J ImmunoTher Cancer (2018) 6:86. doi: 10.1186/s40425-018-0398-7

68. George GC, Barata PC, Campbell A, Yap TA, Cleeland CS, Hong DS, et al. Improving Attribution of Adverse Events in Oncology Clinical Trials. Cancer Treat Rev (2019) 76:33-40. doi: 10.1016/j.ctrv.2019.04.004

69. Kennedy LB. Salama Aks. A Review of Cancer Immunotherapy Toxicity. CA Cancer J Clin (2020) 70:86-104. doi: 10.3322/caac.21596

70. Sivendran S, Latif A, McBride RB, Stensland KD, Wisnivesky J, Haines L, et al. Adverse Event Reporting in Cancer Clinical Trial Publications. J Clin Oncol (2014) 32:83-9. doi: 10.1200/JCO.2013.52.2219

71. Magee DE, Hird AE, Klaassen Z, Sridhar SS, Nam RK, Wallis CJD, et al. Adverse Event Profile for Immunotherapy Agents Compared With Chemotherapy in Solid Organ Tumors: A Systematic Review and MetaAnalysis of Randomized Clinical Trials. Ann Oncol (2020) 31:50-60. doi: 10.1016/j.annonc.2019.10.008
72. Liu A, Hou C, Chen H, Zong X, Zong P. Genetics and Epigenetics of Glioblastoma: Applications and Overall Incidence of IDH1 Mutation. Front Oncol (2016) 6:16. doi: 10.3389/fonc.2016.00016

Conflict of Interest: The authors declare that the research was conducted in the absence of any commercial or financial relationships that could be construed as a potential conflict of interest.

Copyright (c) 2021 Lara-Velazquez, Shireman, Lehrer, Bowman, Ruiz-Garcia, Paukner, Chappell and Dey. This is an open-access article distributed under the terms of the Creative Commons Attribution License (CC BY). The use, distribution or reproduction in other forums is permitted, provided the original author(s) and the copyright owner(s) are credited and that the original publication in this journal is cited, in accordance with accepted academic practice. No use, distribution or reproduction is permitted which does not comply with these terms. 